\title{
Planning and Implementation of Small Hydropower (SHP) Projects
}

\section{S.K. Singal}

Abstract: Small hydropower proj ect is a clean source of power, which India has in abundance. Small hydropower projects are site specific and need careful planning for project formulation and implementation. In this paper an attempt is made to discuss types of small hydropower schemes and present a methodology on planning and implementation of small hydropower projects.

Key words: Feasibility, investigations, planning, project formulation, small hydropower.

\section{Introduction}

Most of the energy we use today comes from fossil fuels. Coal, oil and natural gas are all fossil fuels created several millions of years before by the decay of plants and animals. These fuels lie buried between layers of earth and rock. While fossil fuels are still being created today by underground heat and pressure, they are being consumed more rapidly than they are created. For that reason, fossil fuels are considered as non-renewable; that is, they are not replaced as soon we use them. Moreover burning fossil fuels leads to pollution and many environmental impacts.

Because our world depends so much on energy, we need to use sources of energy that will last forever. These sources are called renewable, as they can be used repeatedly. Renewable energy systems use resources that are constantly replaced and areless polluting. All renewable energy sources - solar, hydropower, biomass and wind - have their origins in activities of the sun.

Hydropower energy is mainly in competition with thermal asa sourceof energy. Becauseoffallingprices on the electro-mechanical equipment during recent years, small and medium-sized hydropower plants are coming under increasing pressure for development. Worldwide, the total hydropower capacity in operation is 848 GW, with annual generation of 3045 TWh/year. The contribution of small hydropower (SHP) in total hydropower installed capacity is about $5 \%$ with 34,000 MW. Presently, hydropower is contributing more than $50 \%$ of electricity supply in about 50

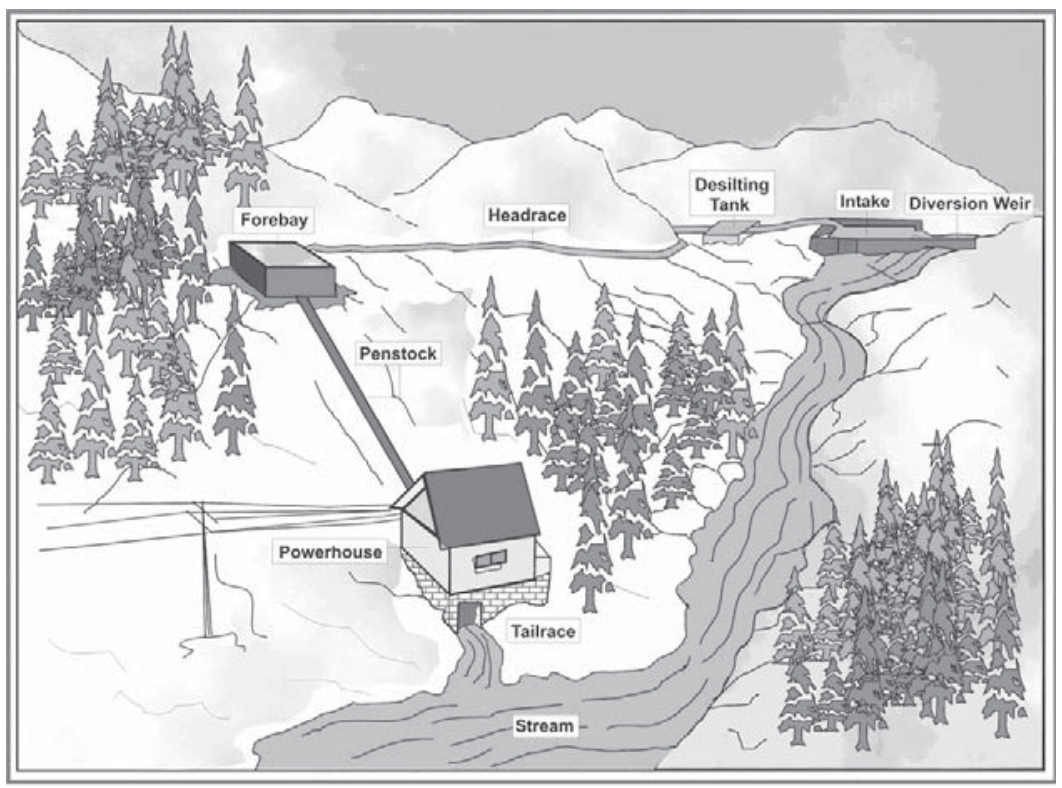

Figure 2. Schematic of Typical Run-of-River SHP Scheme countries (World Atlas and Industry Guide, 2008). In India a potential of 15,000 MW has been estimated in small hydro. About 5,403 potential sites, each having capacity up to $25 \mathrm{MW}$, have been identified in various parts of the country. Already 611 small hydro schemes with a total installed capacity of nearly 2,045 MW are under operation and 225 schemes with another $669 \mathrm{MW}$ are under various stages of implementation (MNRE 2008).

\section{Small Hydropower}

Hydropower is a mature technology developed for more than 100 years. The criterion generally adopted to define the type of hydropower plant is based on installed capacity as follows (CEA 1982, BIS 1991)]:

- Micro hydropower plants: up to $100 \mathrm{~kW}$

- Mini hydropower plants: 101 to 2,000 kW

- Small hydropower plants: $2,001 \mathrm{~kW}$ to $2,5000 \mathrm{~kW}$

- Large hydropower plants: $>25,000 \mathrm{~kW}$

Small hydropower plants can be classified according to their function and based on source of water, as run-of-river, canal-based and dam toe schemes.

Run-of-river plants are those that utilize the instantaneous river flow, having no pondage at its upstream headworks. A weir or a barrage is constructed across the river simply to raise the water level slightly and divert water into a conductor system for power generation. Such a scheme is adopted in the case of a perennial river which has 
minimum dry weather flow of such magnitude that makes the development worthwhile.

Canal-based small hydropower schemes are planned to generate power by utilizing the flow and fall in the canal. These schemes may be planned in the canal itself or in the by-pass channel. These are low head and high discharge schemes. These schemes are associated with advantages such as low gestation period, simple layout, no submergence and rehabilitation problems, and practically no environmental problems (Singal and Saini 2008).

In dam toe SHP plants, head is created by raising the water level behind the dam by storing natural flow and the powerhouse is placed at the toe of the dam or along the axis of the dam on either side. The water is carried to the powerhouse through a penstock. Such schemes utilize the head created by the dam.

\section{Basic Components of SHP Schemes}

There are two basic components in all three types of SHP schemes; i.e., civil works and electro-mechanical equipment. Most of the components are same in different types of schemes; somecomponents, however, aredifferent. based on the specific type of scheme. A broad classification of components is shown in Figure 1 (Nigam 1995).

The components of civil works in run-of-river schemes are more or less same for low head or high head schemes. The basic and common civil works components of run-ofriver schemes are discussed below. A typical layout of runof-river SHP scheme is shown in Fig 2. The key parts of this system include the following:

1) Diversion and intake

2) Desilting tank

3) Power channel

4) Forebay

5) Penstock

6) Powerhouse building

7) Tail race channel

\section{Project Formulation and Planning}

In the pre-construction stage, all the investigation, data collection, project formulation, feasibility study, and report preparation are carried out. Several planning parameters, comprehensive data and information are required for investigation of small hydropower resources and planning of SHP projects. The main data are derived from the studies of topography, hydrology, geology and materials. The steps involved in project formulation and planning are presented in Fig 3.

This stage comprises two parts. In the first part, the pre-feasibility study is carried out based on data collected on topography, hydrology, geology and environmental and socio-economic constraints by a reconnaissance survey of the project area. Any project that is found to be nonfeasible is dropped, while feasible projects are taken up for Part-2 study.

In Part- 2 of SHP development, detailed surveys and investigations on topography, hydrology, geology, material availability, environmental and socio-economic aspects are carried out. Based on the data collected water power analysis, technical and financial details are worked out and a feasibility report is prepared. The feasibility report is a comprehensive document containing project objectives, scope of project, location, topography, hydrology, geological aspects, environmental and socio-economic aspects, details of works such as civil, hydro-mechanical and electrical equipments, broad specifications of the civil works/ equipments, size of components, estimated cost of components, economical and financial analysis. Based on the techno-economical analysis, feasibility of the project is presented.

\section{Project Implementation}

The feasibility report is the logical conclusion of investigations, planning, technical, economic and financial

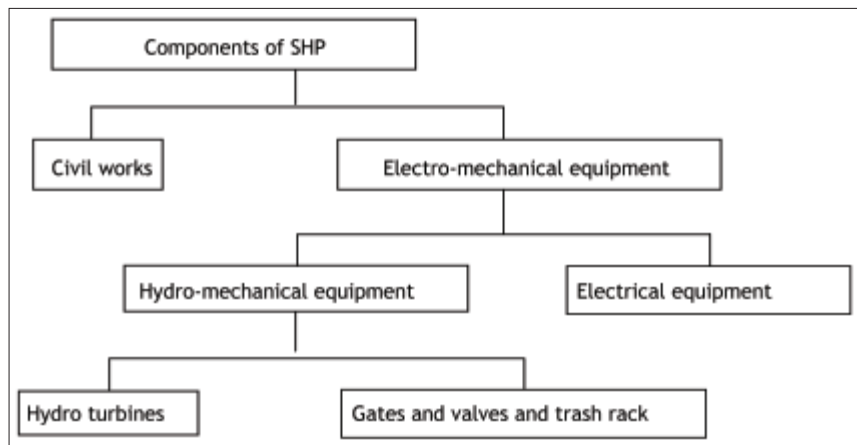

Figure 1. Components of SHP

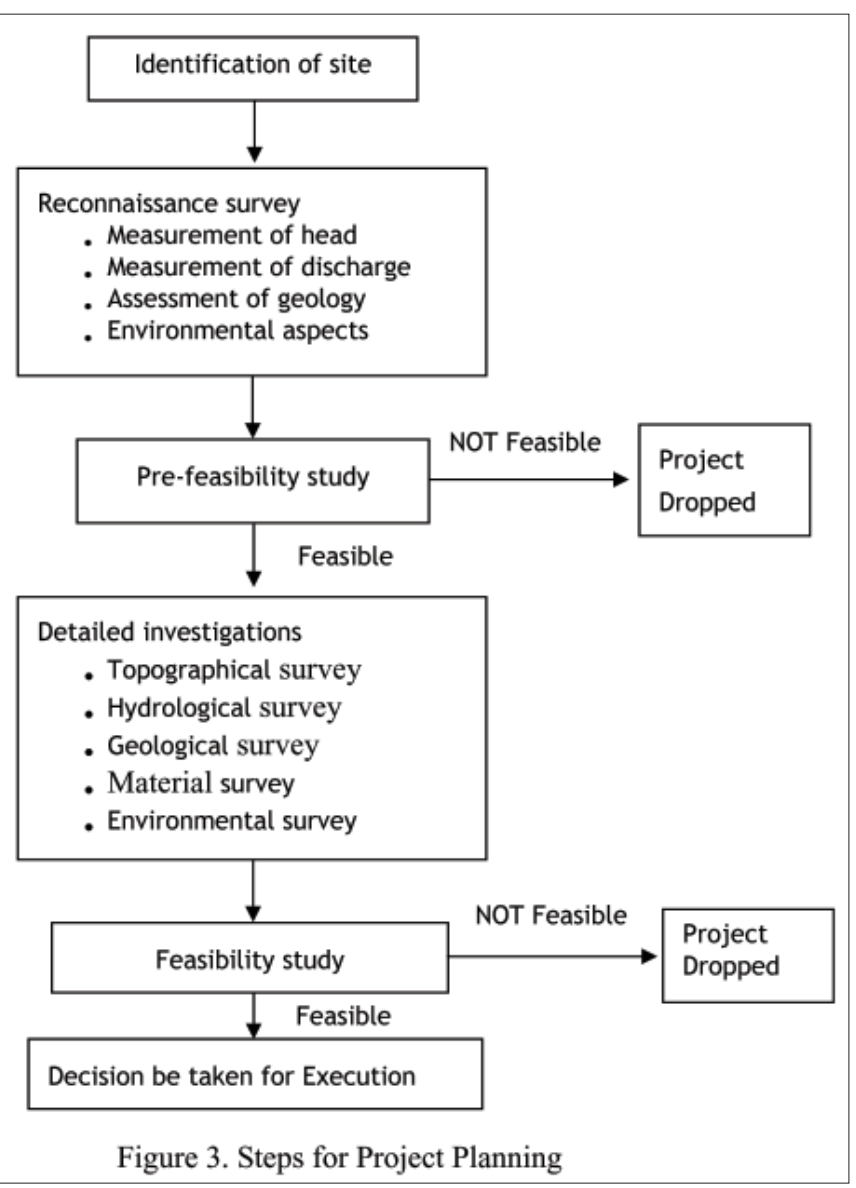


evaluation of SHP projects. Techno-economically proven projects are taken up for the implementation. Following approval of a project for construction and allocation of funds implementation is undertaken. A construction schedule is prepared taking into consideration the availability of manpower, materials and equipment and the rate at which construction funds can be obtained. Execution of the project involves several activities in different stages. The pre-construction stage involves activities such as (1) statutory clearances; i.e., land acquisition, environmental, power evacuation arrangement, and power purchase agreement, (2) engineering designs, and (3) preparation of tender documents, invitation of bids, evaluation of bids and award of the work to the successful bidder.

After the placement of order for construction of civil works and installation of equipment, the construction stage begins. During this stage procurement of materials and equipments, construction of civil works, installation and commissioning of equipment are carried out.

Small hydropower projects are considered as complex projects involving different disciplines for designs, construction, supplies, erection and commissioning of the equipment. For timely implementation of the project, proper coordination, quality control, monitoring of time schedule and financial management are all required. A typical run-of-river SHP project can be divided into five distinct construction areas; viz., diversion weir and intake, desilting tank, headrace channel, forebay with spillway and powerhouse building. The construction program can be planned in such a way that design of works, finalisation of tenders, all the civil engineering works, and electromechanical equipments procurement and erection, testing and commissioning are completed in about 36 months.

Small hydropower projects are capital intensive investments. A successful construction phase requires coordination between design, construction, cash flow and installation of equipment. Any delay in completion of the project will increase the cost of the project. Increase in cost will affect the financial viability of the project. In case a project is delayed by some years the project costs will increase subsequently due to direct, indirect costs and interest during construction, and the project may not be financially viable upon completion.

\section{Pre-construction Activities}

Pre-construction activities of a typical run-of-river SHP project include the following:-

1) Detailed surveys for laying out of various structures, establishing temporary bench marks for use during construction for fixing alignment and levels. The construction drawings will be based on these surveys.

2) Determining soil properties near diversion works, desilting chamber, forebay and powerhouse building.

3) Carrying out in-situ settlement test at powerhouse site.

4) Constructing stores/ warehouse sheds etc.

5) Arranging construction equipment.

6) Pre-qualification of construction agencies (civil contractor). Great emphasis is to be laid on initiating action on these items immediately and completing as early as possible.

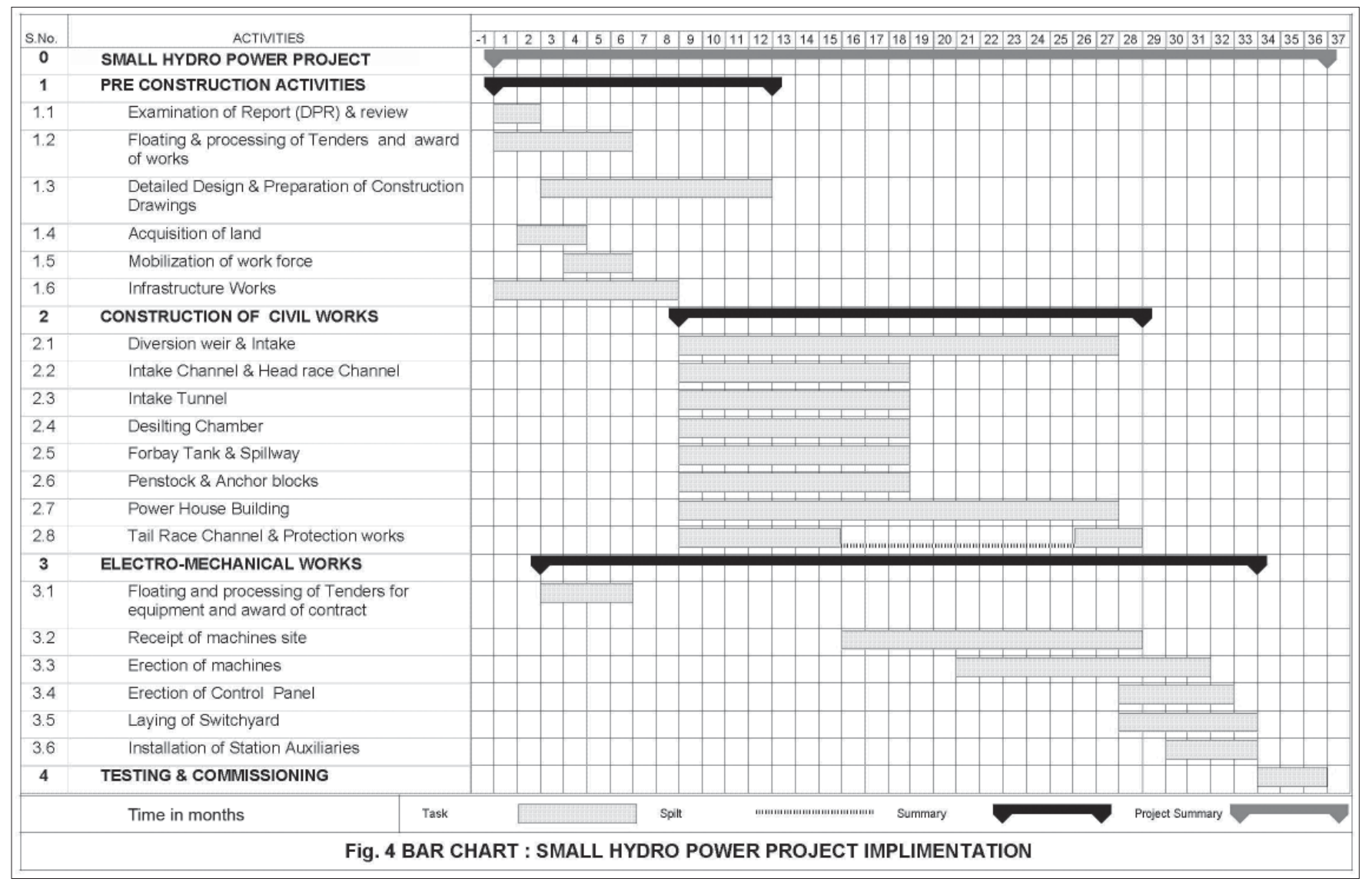


7) Power purchaseagreement: The power generated from the power plant need to be fed to grid for evacuation and power purchase agreement to be signed with the state utility before commissioning of the project. The developer has to give the fixed date of commissioning, as delay on power availability will be liable to be penalized. The energy generation is planned based on hydrological data. In case hydrological analysis is not carried out properly and energy generation falls short of projected values, the power utility will impose penalty for the undelivered power. In case of delay or non availability of grid line for power evacuation, the developer will get benefit of deemed generation. These conditions depend upon the power policy of concerned state government. Thus, it is important to be careful in completing the project in time and having accurate hydrological analysis.

8) Financing: The common mode of financing are developer's equity, loans and subsidy. For arranging loan from financial institutions and getting subsidy from government bodies, developer has to submit detailed project report to them. They assess the project for its financial viability for security of the investment. Leadingfinancial institutions evaluate the project on the base of internal rate of return (IRR). IRR is the discount factor at which present value of benefits is equal to the present value of expenditure. For financially viable project IRR value should be more than the prevailing interest rate. Financial institutions may evaluate the project themselves or by appointing an independent agency. Thus it requires considerable time in arranging finances for the project.

9) Environmental clearance: Such clearances are given by Ministry of Environment and Forest, Govt. of India. For projects costing up to 1000 million Indian rupees, it is not mandatory, however for developing project in reserve forest area such clearance is required which may need considerable time. In case some trees are cut for

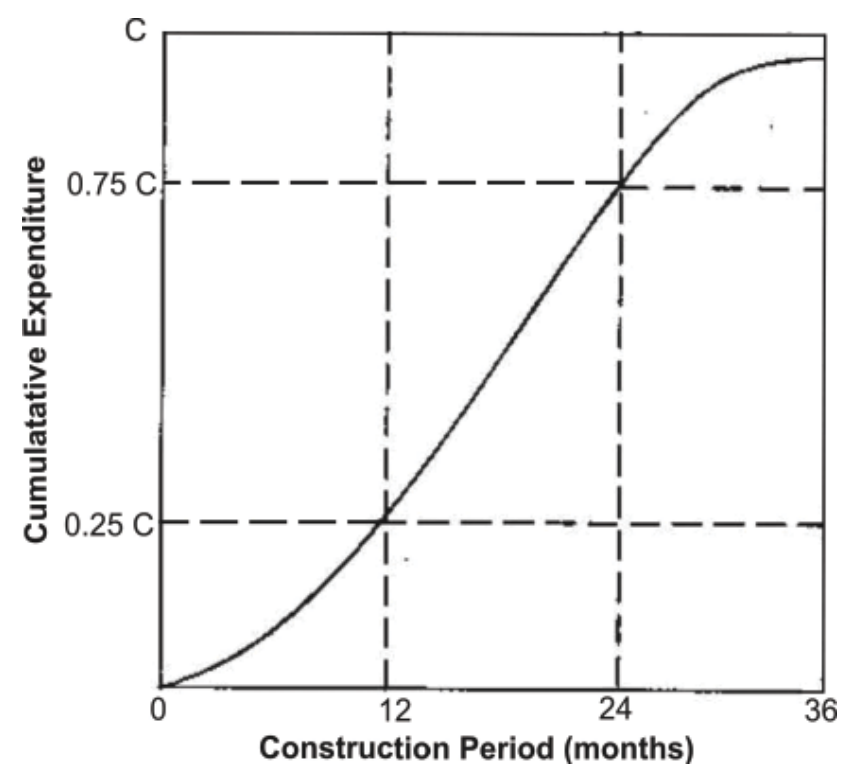

Figure 5. Cash Flow 'S' Curve constructing the project components, developer should plant more trees to take care of ecological balance.

\section{Construction Materials}

The natural occurring materials like stones required for either stone masonry and for manufacturing of aggregate and sand, screened gravel and sand are generally available in the nearby area. Their exact sources, however, have to be determined after carrying out necessary tests for their acceptance. Planning and procurement of items like cement, steel and timber have also to be initiated in time.

\section{Manufactured Items}

The manufactured or purchased items include:

1) Fabricated structures like trash rack, penstocks, gates, roof trusses or chain pulley block and their fittings.

2) Generating equipment-turbine, governor, generator, control panels, switchgear, and other auxiliary equipment.

3) Theother bought outitems likepipes, valves, ventilation equipment, fire fighting equipment, lighting fittings/ accessories and other building accessories.

These items are to be procured by competitive bidding along with other project works or separately.

\section{Construction Program}

Construction program/schedule for execution of a runof-river SHP project is given in Figure 4 in the form of bar chart. Following assumptions have been made in this program.

1) The tenders for civil work will be invited at least by third month after the project is started. The works allotted by sixth month and actual construction shall start by the start of ninth month.

2) Tenders for the supply of powerhouse equipment will be floated in third month and contracts be awarded in sixth month.

3) The delivery period at site of power generating equipment will be about nine months after awarding the contract.

4) The necessary infrastructure will be completed by the end of 8 months.

The construction program gives sequencing and completion time of activities. It does not depict the cash flow of expenditure (C). The Cash Flow ' $\mathrm{S}$ ' curve is used to forecast the cash requirements of a project. The cumulative expenditure for a project normally takes the shape of the letter 'S'. By plotting the cumulative expenditure against cumulative project duration, project cash requirements can be calculated. This 'S' curve shape arises, during early construction stage due to lesser number of activities and hence, the expenditure curve is relatively flat. As other activities commence, expenditure increases and the curve develops into the steeper middle portion. Towards the end of the project, many activities will be completed and there will be a rundown of construction work, resulting in a flattened curve. A typical ' $S$ ' curve is shown in Figure 5. About $25 \%$ of expenditure represents the activity build-up 
period of $1 / 3 r d$ of the construction period and a further quarter occupies the rundown period of one-third contract period. Half of the cumulative expenditure is gained over the center one-third of the 'S' curve (Seetharaman 2007). In addition, the $S$ curve is an important tool for the monitoring of the construction works/ projects.

\section{Interaction with Local People}

During planning and execution of the project, local people should be taken into confidence and their participation in the development should be ensured. When people are consulted and involved in projects, they develop a bonding with it. They identify themselves closely with the project and may cooperate in its implementation. Cost of the project comes down when we employ local labor, utilize community assets like land and other infrastructure. Willing local people should be trained for operation and maintenance so that the recurring expenditure on running the plant is reduced. Poor or no interaction with local people may lead to the problems for project developers, as the people may feel that somebody else is utilizing their resources, whereupon they may ask for huge and undue compensation. This may lead to public unrest and agitation which causes time and cost overrun.

\section{Experience in other Countries: China}

China has used small hydropower source for rural electrification. The Chinese government has given numerous preferential policies and measures to encourage SHP development. These include tax reductions, soft loans and grants, the promotion of private firms to invest in SHP stations, and policies to protect supply areas and private property. Unlike the centralized development model in other developing countries, or commercially-oriented development in some industrialized countries, most SHP development in China is focused on decentralized management. SHP development strategies, objectives, standards and policies are decided by the central government, while planning, construction, design, operation, management, and so on are undertaken by the local governments. This decentralized management mechanism results in the complementary coexistence of national grid development, local grid development and isolated SHP stations (Sinha 2007).

\section{Conclusions}

The project planning study requires substantial investment in terms of time, efforts and finances to determine the feasibility of the project. After carrying out all these efforts, if the project is found techno-economically non-viable, all the investments made will become a waste exercise. Therefore, in pre-feasibility stage assessment of cost and technical parameters should be worked out carefully so that only feasible projects are undertaken for detailed investigations and implementation.

S.K. Singal, holds BE (Civil) degree from Indian Institute of Technology, Roorkee, India in 1983 and M.E (Earthquake Engineering) University of Roorkee(UR). Hejoined Alternate Hydro Energy Centre (AHEC), UR in 1984 as scientist. Presently, he is working as Senior Scientific Officer in AHEC. He has research and teaching experience of more than 25 years in the field of Small Hydropower. He has guided 23 M. Tech. Theses, contributed 75 research papers in International and national journals and conferences. He has organized more than 25 short term training courses on different aspects of small hydropower and water resources, and has delivered expert lectures in more than 75 training program for international and national in service engineers.

Correspondence address:

sunilfah@iitr.ernet.in, sunilksingal@gmail.com

\section{References}

MNRE, 2008,Annual Report2007-08,NewDelhi, Government of India, Ministry of New and Renewable Energy.

CEA, 1982, Guidelines for Development of Small HydroElectric Schemes, New Delhi: Government of India.

BIS, 1991, Guidelines for the Selection of Hydraulic Turbine, Preliminary Dimensioning and Layout of Surface HydroElectric Power Houses (Small, Mini and Micro Hydro-Electric Power House), BIS: 12800 (Part 3), New Delhi: Bureau of Indian Standards.

Nigam, P.S., 1995, Handbook of Hydro-Electric Engineering, Roorkee, India: Nem Chand and Brothers.

Seetharaman S., 2007, Construction Engineering and Management, New Delhi: Umesh Publications.

Singal S.K. and R.P. Saini, 2008, 'Analytical approach for development of correlations for cost of canal based SHP schemes', Renewable Energy 33:2549-2558.

Sinha S.M., "Private Participation and State Policies in Developing Small Hydro as Alternate Source of Energy in Developing Countries", Hydro Sri Lanka, Oct. 22-24, 2007

World Atlas and Industry Guide, 2008, International J ournal on Hydropower and Dams. 